\title{
Delayed settling of marine snow at sharp density transitions driven by fluid entrainment and diffusion-limited retention
}

\author{
Jennifer C. Prairie ${ }^{1,2,3, *}$, Kai Ziervogel ${ }^{1}$, Carol Arnosti $^{1}$, Roberto Camassa $^{2,3}$, \\ Claudia Falcon $^{2,3}$, Shilpa Khatri ${ }^{2,3}$, Richard M. McLaughlinn ${ }^{2,3}$, Brian L. White ${ }^{1,3}$, \\ Sungduk $\mathrm{Yu}^{1,3}$
}

${ }^{1}$ Department of Marine Sciences, ${ }^{2}$ Carolina Center for Interdisciplinary Applied Mathematics, Department of Mathematics, and ${ }^{3}$ Joint Fluids Lab, University of North Carolina at Chapel Hill, Chapel Hill, North Carolina 27599, USA

\begin{abstract}
Marine snow is central to the marine carbon cycle, and quantifying its small-scale settling dynamics in different physical environments is essential to understanding its role in biogeochemical cycles. Previous field observations of marine aggregate thin layers associated with sharp density gradients have led to the hypothesis that these layers may be caused by a decrease in aggregate settling speed at density interfaces. Here, we present experimental data on aggregate settling behavior, showing that these particles can dramatically decrease their settling velocity when passing through sharp density transitions. This delayed settling can be caused by 2 potential mechanisms: (1) entrainment of lighter fluid from above as the particle passes through the density gradient, and (2) retention at the transition driven by changes in the density of the particle due to its porosity. The aggregates observed in this study exhibited 2 distinct settling behaviors when passing through the density transition. Quantitatively comparing these different behaviors with predictions from 2 models allow us to infer that the delayed settling of the first group of aggregates was primarily driven by diffusion-limited retention, whereas entrainment of lighter fluid was the dominant mechanism for the second group. Coupled with theory, our experimental results demonstrate that both entrainment and diffusion-limited retention can play an important role in determining particle settling dynamics through density transitions. This study thus provides insight into ways that delayed settling can lead to the formation of aggregate thin layers, important biological hotspots that affect trophic dynamics, and biogeochemical cycling in the ocean.
\end{abstract}

KEY WORDS: Aggregation · Thin layer · Accumulation · Biophysical coupling $\cdot$ Hotspots

\section{INTRODUCTION}

Marine snow plays a critical role in the marine carbon cycle, as a dominant component of carbon flux from the surface ocean, a site of enhanced bacterial activity, and often an important food source for zooplankton (Alldredge \& Silver 1988, Smith et al. 1992,
Simon et al. 2002, Kiørboe 2011). Knowledge of the vertical distribution of marine aggregates in the water column, as well as of the factors that underlie these distributions, are critical to understanding the functions of aggregates in the ocean.

Recent studies have observed that thin layers of aggregates - with concentrations several times back- 
ground levels - are common in coastal waters (MacIntyre et al. 1995, Alldredge et al. 2002, Prairie et al. 2010), and are often associated with sharp density transitions (MacIntyre et al. 1995, Dekshenieks et al. 2001, Prairie et al. 2010). These layers can have significant consequences for local carbon cycling, since aggregates may act as hot spots for bacterial activity or foraging zooplankton (Green \& Dagg 1997, Kiørboe 2000, Ziervogel \& Arnosti 2008, Ziervogel et al. 2010). Some studies have suggested that a possible explanation for the formation of these layers is locally decreased settling speeds as particles pass through these regions of sharp stratification (Derenbach et al. 1979, Alldredge \& Crocker 1995, MacIntyre et al. 1995).

Previous theoretical and experimental studies have investigated the effect of sharp stratification on settling particles, and have shown that there are 2 potential mechanisms that could explain a decrease in settling velocity for a particle falling through a density transition. Studies with solid spheres have demonstrated that a sphere passing through a density transition will entrain lighter fluid from above in a thin boundary layer shell around the particle, and the additional buoyancy can decrease its settling velocity - in some cases even cause it to temporarily reverse direction (Srdi -Mitrovi et al. 1999, Abaid et al. 2004, Camassa et al. 2009, 2010, Yick et al. 2009). This delayed settling due to entrainment of lighter fluid can be seen in Fig. 1A, a sequence of previously published images from experiments with solid spheres along with matching theory (Camassa et al. 2010). However, marine aggregates are extremely porous (usually containing $>99.5 \%$ water by volume; Ploug \& Passow 2007), providing for another potential mechanism for delayed settling. The density of a porous particle will change depending on the fluid surrounding it. Thus, a porous particle may encounter a sharp density transition such that the particle is initially too light to sink through the density transition; however, after denser fluid diffuses into the particle, its density may increase sufficiently such that it can continue to sink. This diffusion-limited retention of porous particles, depicted schematically in Fig. 1B, has been investigated theoretically (MacIntyre et al. 1995, Alldredge \& Crocker 1995, Kindler et al. 2010) and experimentally using agarose spheres (Kindler et al. 2010).

This recent work with both solid and porous spheres has provided important insight into the potential for sharp density gradients to lead to accumulations of aggregates through delayed settling. However, there is a lack of experimental work investigating whether natural aggregates will exhibit the same behavior as artificial particles, since natural aggregates differ from artificial spheres in important aspects including composition, shape, density, and size. In addition, it remains unclear which of the proposed mechanisms for delayed settling (i.e. entrainment of lighter fluid or diffusion-limited retention) dominates aggregate settling behavior for different types of aggregates in different environments.

Here, we present experimental results demonstrating that natural aggregates formed in the laboratory can significantly decrease their settling velocity as they pass through sharp density transitions. Our results demonstrate 2 distinct settling behaviors; one suggestive of diffusion-limited retention, and one suggestive of entrainment of lighter fluid. Although our experimental conditions are directly comparable only to a subset of field conditions, the general dynamics underlying the observed behavior is applicable to a wide range of aggregates settling through sharp density gradients. By comparing our results with those of previously developed models, we determined the mechanism that plays a dominant role depends on aggregate size, settling velocity, and the vertical density gradient. Lastly, we discuss the implications for the delayed settling of aggregates by each mechanism to form a layer that can act as a hot spot for foraging zooplankton and carbon remineralization.

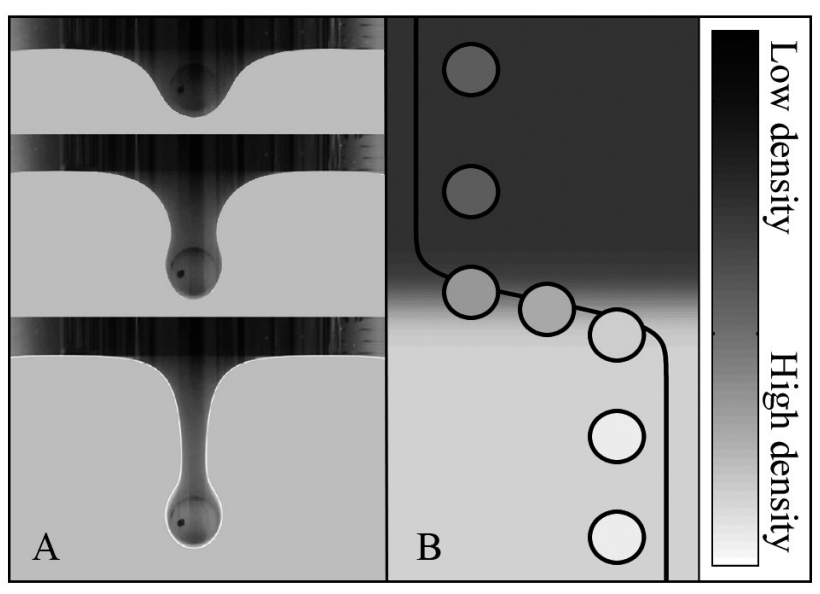

Fig. 1. Two mechanisms for decreased settling velocity of aggregates as they pass through sharp density transitions. (A) Lighter fluid is entrained around the sinking particle causing it to slow as shown in a time series of 3 experimental images (along with comparisons to theory). Figure from Camassa et al. (2010). (B) The aggregate pauses at the density transition until diffusion of denser fluid into the porous aggregate increases its density allowing it to continue sinking.

Schematic adapted from figure in Kindler et al. (2010) 


\section{MATERIALS AND METHODS}

\section{Formation of aggregates}

Aggregates were formed in a rotating acrylic cylindrical tank (total volume $\sim 4$ l) filled with either river water or seawater and placed on a roller table. This approach is widely used for aggregate formation in the lab (Shanks \& Edmondson 1989, Jackson 1994, Ziervogel \& Forster 2005, Ploug et al. 2008, Ziervogel \& Arnosti 2008, Ziervogel et al. 2010). We chose to use aggregates formed from both fresh water and seawater to observe the settling behavior of a wider range of aggregate types with different densities and compositions. Aggregates are derived from natural organic matter present in the source water, and riverine and marine dissolved and particulate organic matter differ in their sources and composition (Hedges \& Oades 1997, Cauwet 2002), although the specific composition of the organic matter in the source water was not measured in this study.

River water was collected in October 2011 at the mouth of the Tar River, North Caroline (NC) USA. Seawater was collected in December 2011 from the pier at the University of North Carolina Institute of Marine Sciences, located in Morehead City, NC. Particles were visible in both water samples prior to roller table experiments, which were started in the laboratory at room temperature shortly after sample collection. Rotation speed of the tank was set to $3.5 \mathrm{rpm}$, which proved suitable for forming aggregates useable in settling experiments. Macroscopic aggregates formed within the first day of both experiments. Aggregates were incubated in roller tanks for $7 \mathrm{~d}$ (seawater) and $17 \mathrm{~d}$ (river water); the time of incubation reflected the length of time required to form aggregates that were stable enough to use in settling experiments. At the end of the incubation, roller tanks were placed upright, and single aggregates that settled to the bottom of the tank were individually removed via volumetric pipette from the tank water (hereafter referred to as aggregate ambient water), and analyzed separately for their settling behavior. Four settling experiments were conducted in total-one with freshwater aggregates (Expt 1) and 3 with seawater aggregates (Expts 2, 3, and 4).

\section{Measuring aggregate size}

Aggregates used for calculation of aggregate densities as well as aggregates used in the 2-layer settling experiments were first measured by micro- scopy. Individual aggregates were placed on top of a millimeter square grid in a Petri dish with water of density approximately equal to that of their ambient water. Aggregates were then photographed with a digital microscope (Model 26700-300, Aven), producing images of the 2-dimensional projection of the aggregate (Fig. 2A). Images were processed using MATLAB to determine the cross-sectional area (Fig. 2B), which was used to calculate the equivalent spherical diameter for each aggregate, i.e. the cross sectional area was assumed to represent that of a sphere with an equivalent cross-sectional area (see Table 2). Since the aggregates are irregularly shaped and are most likely to lie such that their largest crosssection is the area imaged, the estimates of equivalent spherical diameter for each aggregate are likely overestimated. In addition, the irregular shape of the aggregates has consequences for their surface area to volume ratio, which would be much larger than an equivalently sized sphere. The implications of these factors on the delayed settling behavior of the aggregates are discussed below when comparing the experimental delayed settling behavior to models.

\section{Calculating aggregate densities}

Aggregate densities were calculated by measuring the sinking velocity of 5 to 12 representative aggregates per experiment in water of homogenous density (given in Table 1) approximately equal to that of their ambient water $\left(\sim 0.998 \mathrm{~g} \mathrm{~cm}^{-3}\right.$ for freshwater aggregates and $\sim 1.025 \mathrm{~g} \mathrm{~cm}^{-3}$ for marine aggregates). All water densities were measured using a DMA 35 Portable Density Meter (Anton Paar). After measuring their sizes as described above, individual aggregates were gently transferred by pipette to a rectangular tank with a base $18 \times 18 \mathrm{~cm}$ and a height of $32 \mathrm{~cm}$. The path of the aggregate as it settled in the tank was recorded using a Pike F-100B camera

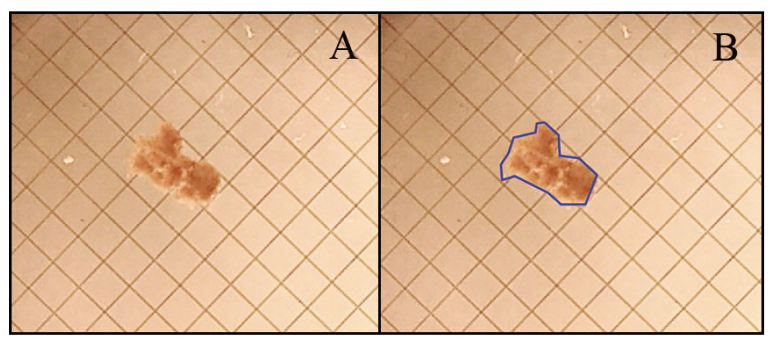

Fig. 2. (A) Microscope image of the aggregate shown on a $1 \mathrm{~mm}^{2}$ grid. (B) Same image as (A) with perimeter outlined to illustrate how cross-sectional area is approximated to derive equivalent spherical diameter of aggregates 
Table 1. Aggregate sinking experiments. Aggregate density was calculated using Eq. (1). Average aggregate density is shown over $\mathrm{n}$ aggregates along with the standard deviation. The subsequent columns provide the density of the homogenous water used to calculate aggregate densities, the densities of the top and bottom layer of the 2-layer settling experiments, and the number of aggregates observed in the 2-layer settling experiments. Aggregate excess density in bottom layer gives the difference between the average aggregate density and the density of the bottom layer

\begin{tabular}{|c|c|c|c|c|c|c|}
\hline $\begin{array}{l}\text { Expt } \\
\text { no. }\end{array}$ & $\begin{array}{l}\text { Average aggregate } \\
\text { density }\left(\mathrm{g} \mathrm{cm}^{-3}\right)\end{array}$ & $\begin{array}{l}\text { Density of water } \\
\text { for aggregate density } \\
\text { measurement } \\
\left(\mathrm{g} \mathrm{cm}^{-3}\right)\end{array}$ & $\begin{array}{l}\text { Density } \\
\text { of top } \\
\text { layer } \\
\left(\mathrm{g} \mathrm{cm}^{-3}\right)\end{array}$ & $\begin{array}{l}\text { Density } \\
\text { of bottom } \\
\text { layer } \\
\left(\mathrm{g} \mathrm{cm}^{-3}\right)\end{array}$ & $\begin{array}{c}\text { No. of } \\
\text { aggregates }\end{array}$ & $\begin{array}{l}\text { Aggregate } \\
\text { excess } \\
\text { density } \\
\left(\mathrm{g} \mathrm{cm}^{-3}\right)\end{array}$ \\
\hline 1 & $1.0098 \pm 0.0064(n=12)$ & 0.9985 & 0.9985 & 1.0401 & 5 & -0.0303 \\
\hline 2 & $1.0598 \pm 0.0102(\mathrm{n}=5)$ & 1.0261 & 1.0248 & 1.0404 & 7 & 0.0194 \\
\hline 3 & $1.0606 \pm 0.0145(n=10)$ & 1.0256 & 1.0249 & 1.0352 & 12 & 0.0254 \\
\hline 4 & $1.0599 \pm 0.0112(n=10)$ & 1.0253 & 1.0250 & 1.0460 & 15 & 0.0139 \\
\hline
\end{tabular}

(Allied Vision Technologies) recording at a rate between 25 and 33 frames $^{-1}$ (but that remained constant within an experiment). Sinking velocity was calculated from the vertical displacement (captured at the recording rate of the camera) and then an average sinking velocity $(U)$ was calculated over at least 3 continuous seconds. This was used to estimate aggregate density $\left(\rho_{\mathrm{a}}\right)$ using the following equation (Batchelor 1967, Ploug et al. 2008):

$$
U=\sqrt{\frac{4 g\left(\rho_{\mathrm{a}}-\rho_{\mathrm{f}}\right) d}{3 \rho_{\mathrm{f}} C_{\mathrm{D}}}}
$$

where $g$ is the acceleration due to gravity, $\rho_{\mathrm{f}}$ is the density of the fluid, $C_{D}$ is the drag coefficient, and $d$ is the equivalent spherical diameter as measured from the microscope images. The drag coefficient was calculated using the following empirical drag law (White 1974):

$$
C_{\mathrm{D}}=\frac{24}{\mathrm{Re}}+\frac{6}{1+\mathrm{Re}^{0.5}}+0.4
$$

for $\operatorname{Re}>0.5$ where Re is the Reynolds number calculated as:

$$
\operatorname{Re}=\frac{d U}{v}
$$

where $v$ is the kinematic viscosity of water $(1.19 \times$ $10^{-2} \mathrm{~cm}^{2} \mathrm{~s}^{-1}$ at $15^{\circ} \mathrm{C}_{i}$ Ploug et al. 2008). Since the above equations assume spherical particles, aggregates used to estimate aggregate density were chosen to be as spherical as possible. Individual densities for all aggregates measured were then averaged to obtain an average $\rho_{\mathrm{a}}$ for each experiment (Table 1). Since aggregates are porous, their densities depend on the fluid in which they are measured; the aggregate densities reported here are estimated in water approximately the density of the ambient water in which they were originally formed (see Table 1).

\section{Two-layer aggregate settling experiments}

After an average aggregate density was calculated, different aggregates from the same roller table batch were observed as they settled through a 2-layer water column with a sharp density transition in the middle. The tank used in these experiments had a square base $(30 \times 30 \mathrm{~cm})$ and had a height of $61 \mathrm{~cm}$. The tank was filled to approximately $20 \mathrm{~cm}$ with salt water. This salt water, hereafter defined as the bottom layer fluid, varied in density from experiment to experiment but was always more dense than the water in which the aggregates were formed (Table 1). After the bottom layer fluid was still, water with density approximately equal to that of the aggregates' ambient water-defined as the top layer fluid-was carefully poured on top of the bottom layer fluid through a diffuser initially soaked with top layer fluid. The diffuser floats at the surface of the water column; it is $\sim 2 \mathrm{~cm}$ thick and is constructed of foam and sponge to slow down the flow of top layer fluid as it is introduced into the tank in order to create a sharp density transition between the top layer and bottom layer fluid. The thickness of the density transition was not measured for these experiments but is estimated from previous application of this stratification method (Abaid et al. 2004, Camassa et al. 2009) to be between 1 and $2 \mathrm{~cm}$ thick. Variations in this thickness will affect the sharpness of the density gradient, which is likely to affect aggregate settling behavior, although future work investigating this dependence is needed to determine the exact effect. The vertical density difference is calculated as the difference between the density of the bottom layer fluid $\left(\rho_{\mathrm{BL}}\right)$ and the density of the top layer fluid $\left(\rho_{\mathrm{TL}}\right)$ and ranged between 0.0103 and $0.0416 \mathrm{~g} \mathrm{~cm}^{-3}$. For each experiment, the initial excess density of the aggregates in the bottom layer was calculated as $\rho_{a}-$ $\rho_{\mathrm{BL}}$ and is given in Table 1. 

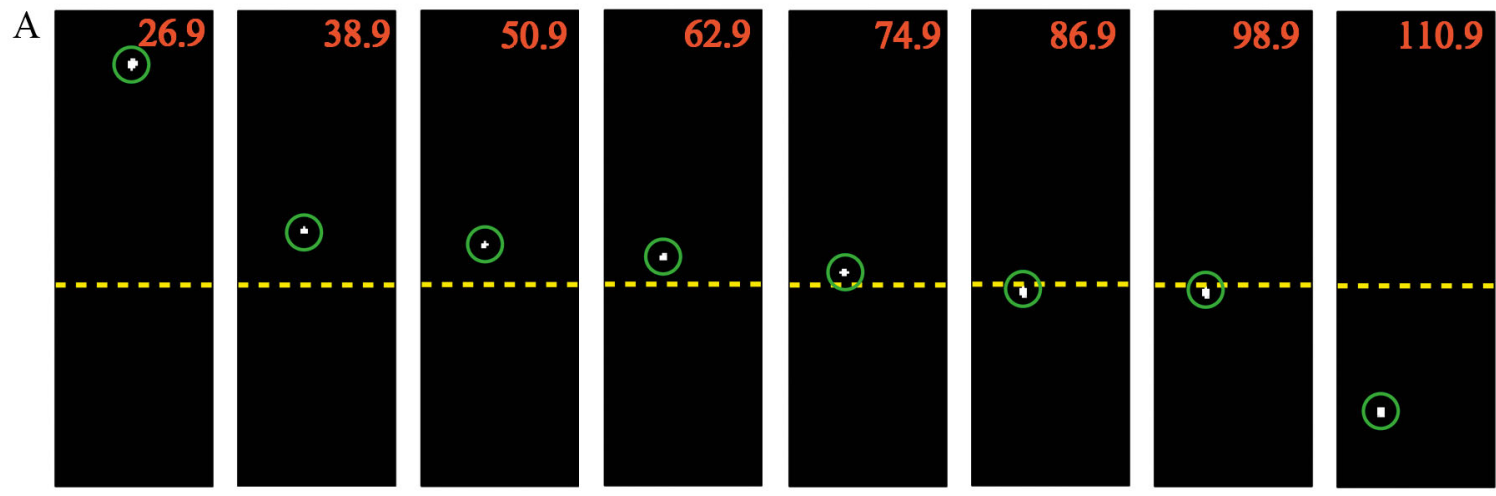

B
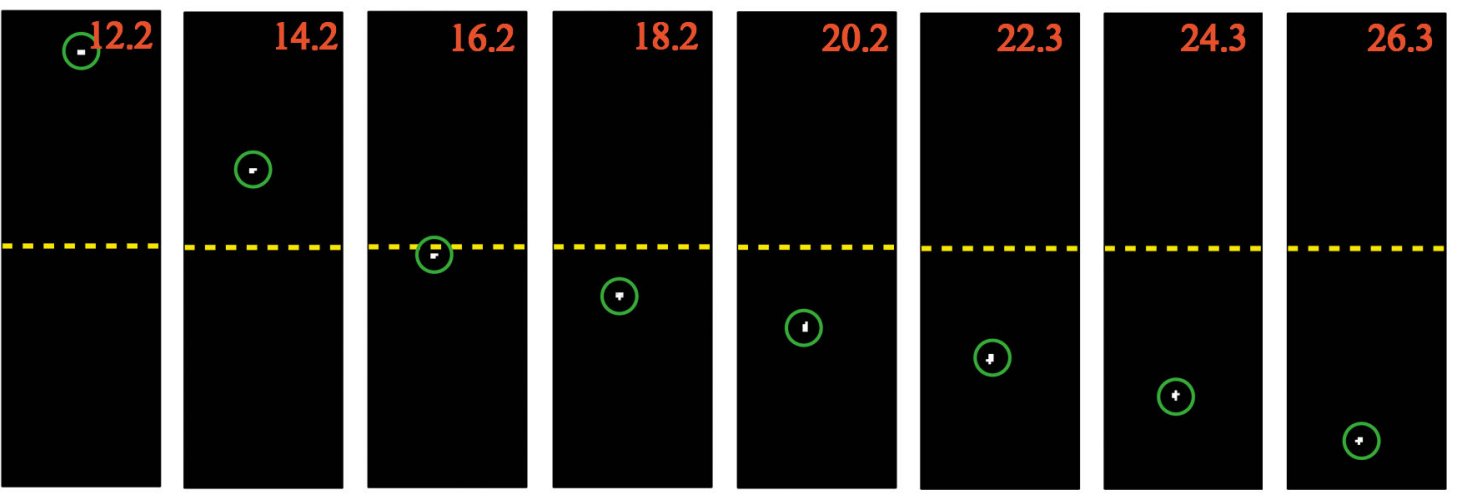

Fig. 3. Sequential panels show a region of images from (A) Expt 1 (Aggregate 4) and (B) Expt 4 (Aggregate 7) as the aggregate passes through the density transition (dotted yellow line). Time between images is $\sim 12 \mathrm{~s}$ for (A) and $\sim 2 \mathrm{~s}$ for (B). Time stamps are shown in orange in seconds. The region shown is $\sim 2 \mathrm{~cm} \times 6 \mathrm{~cm}$. The aggregate in (A) demonstrates a smaller minimum settling velocity and a much longer delayed settling time than the aggregate in (B)

Aggregates were transferred gently by pipette into the 2-layer water column one at a time to observe their settling behavior. Aggregate settling behavior was recorded using the Pike camera, recording at a frame rate that was constant within runs, but varied among runs between 12 and 25 frames $\mathrm{s}^{-1}$. Recordings were conducted with the room dark and the tank lit from the sides, using light-emitting diode (LED) strips attached to 2 panels that spanned the height and width of the tank. Although the LED panels did introduce some heat laterally into the tank, measurements indicate that the rise in temperature was slight $\left(<1^{\circ} \mathrm{C}\right.$ over the course of an experiment) and any convective motion was negligible in comparison to aggregate settling velocities. The square field of view of the images had dimensions which ranged among experiments between $31.5 \mathrm{~cm} \times 31.5 \mathrm{~cm}$ and $37.2 \mathrm{~cm} \times 37.2 \mathrm{~cm}$. The top of the field of view was positioned between $\sim 11.5$ and $17 \mathrm{~cm}$ above the density transition (varied between experiments but kept constant within each experiment). The size of the field of view was chosen to maximize the vertical distance that the aggregate could be tracked while retaining adequate resolution of the aggregate.

\section{Data analysis}

All images (Fig. 3) were processed in MATLAB to determine the location of the aggregate (defined as the location of its centroid) over time. Position data was linearly corrected from pixels to cms using the measured dimensions of the field of view of the camera. The settling velocity was calculated by dividing the aggregate's vertical displacement between sequential images by the time between images; the settling velocity was then smoothed using a moving average over approximately a $1 \mathrm{~s}$ span.

The settling velocity in the top layer was calculated by averaging the smoothed settling velocity in a region above the density transition where the velocity was relatively constant for a period of at least $2 \mathrm{~s}$. The settling velocity in the bottom layer was calculated by averaging the smoothed settling velocity in the very last part of the settling velocity time record (for a period of at least $2 \mathrm{~s}$ ), representing the point at which the aggregate had reached its terminal velocity after passing through the density transition. The aggregates in Expt 1 did not appear to fully reach their terminal velocity in the bottom layer; in these 
cases, settling velocity in the bottom layer was likely underestimated. Measured settling velocities for each aggregate are reported in Table 2 ; it is important to note that these measured values are not expected to match theoretical sinking velocity values (as calculated from Eq. 1) given the wide range of aggregate shapes observed in these experiments, and that an average aggregate density was used for each experiment.

Two metrics were calculated to determine the extent to which the aggregate's settling velocity de- creased within the density transition. The normalized minimum settling velocity (NMSV) was calculated as the minimum value of the smoothed settling velocity (MSV) divided by the settling velocity in the bottom layer. The delayed settling time (DST) was calculated as the length of time that the aggregate's smoothed settling velocity was less than $90 \%$ of the settling velocity in the bottom layer. This definition for DST was chosen because it quantified the time of delayed settling of the aggregate independent of its settling velocity; the threshold of $90 \%$ was chosen to obtain a

Table 2. For each aggregate from the four 2-layer sinking experiments, experimental results are reported, including equivalent spherical diameter, settling velocity in the top and bottom layer, normalized minimum settling velocity (NMSV), delayed settling time (DST), and Reynolds number (Re) in the top layer

\begin{tabular}{|c|c|c|c|c|c|c|c|}
\hline $\begin{array}{l}\text { Expt } \\
\text { no. }\end{array}$ & $\begin{array}{c}\text { Aggregate } \\
\text { no. }\end{array}$ & $\begin{array}{l}\text { Aggregate equivalent } \\
\text { spherical diameter } \\
\qquad(\mathrm{cm})\end{array}$ & $\begin{array}{l}\text { Settling velocity } \\
\text { in top layer } \\
\left(\mathrm{cm} \mathrm{s}^{-1}\right)\end{array}$ & $\begin{array}{c}\text { Settling velocity } \\
\text { in bottom layer } \\
\left(\mathrm{cm} \mathrm{s}^{-1}\right)\end{array}$ & NMSV & $\begin{array}{l}\mathrm{DST} \\
(\mathrm{s})\end{array}$ & $\begin{array}{c}\mathrm{Re} \\
\text { in top layer }\end{array}$ \\
\hline \multirow[t]{5}{*}{1} & 1 & 0.206 & 0.62 & 0.42 & -0.01 & 244.2 & 10.7 \\
\hline & 2 & 0.658 & 0.75 & 0.48 & -0.15 & 600.6 & 41.3 \\
\hline & 3 & 0.144 & 0.73 & 0.47 & -0.01 & 191.4 & 8.8 \\
\hline & 4 & 0.101 & 0.51 & 0.40 & 0 & 104.6 & 4.3 \\
\hline & 5 & 0.137 & 0.52 & 0.41 & 0 & 149.8 & 5.9 \\
\hline \multirow[t]{7}{*}{2} & 1 & 0.089 & 1.48 & 0.87 & 0.65 & 6.6 & 11.0 \\
\hline & 2 & 0.150 & 1.39 & 1.09 & 0.62 & 6.9 & 17.4 \\
\hline & 3 & 0.122 & 1.23 & 0.89 & 0.57 & 11.2 & 12.6 \\
\hline & 4 & 0.138 & 1.01 & 0.83 & 0.45 & 12.5 & 11.7 \\
\hline & 5 & 0.071 & 0.97 & 0.79 & 0.67 & 6.6 & 5.8 \\
\hline & 6 & 0.064 & 0.89 & 0.55 & 0.54 & 13.0 & 4.8 \\
\hline & 7 & 0.096 & 1.22 & 0.81 & 0.58 & 9.5 & 9.9 \\
\hline \multirow[t]{12}{*}{3} & 1 & 0.077 & 0.50 & 0.50 & 0.30 & 18.9 & 3.2 \\
\hline & 2 & 0.051 & 0.39 & 0.38 & 0.51 & 9.2 & 1.7 \\
\hline & 3 & 0.062 & 0.55 & 0.53 & 0.54 & 9.9 & 2.8 \\
\hline & 4 & 0.056 & 0.44 & 0.43 & 0.40 & 13.4 & 2.1 \\
\hline & 5 & 0.112 & 0.88 & 0.82 & 0.63 & 8.5 & 8.3 \\
\hline & 6 & 0.108 & 0.70 & 0.66 & 0.48 & 15.0 & 6.4 \\
\hline & 7 & 0.098 & 1.09 & 0.98 & 0.79 & 3.5 & 9.0 \\
\hline & 8 & 0.138 & 1.06 & 0.95 & 0.74 & 1.0 & 12.3 \\
\hline & 9 & 0.105 & 0.85 & 0.77 & 0.67 & 7.9 & 7.5 \\
\hline & 10 & 0.166 & 1.56 & 1.34 & 0.89 & 1.1 & 21.6 \\
\hline & 11 & 0.116 & 0.86 & 0.80 & 0.64 & 9.2 & 8.4 \\
\hline & 12 & 0.110 & 0.92 & 0.85 & 0.71 & 7.5 & 8.5 \\
\hline \multirow[t]{15}{*}{4} & 1 & 0.100 & 0.57 & 0.54 & 0.08 & 45.4 & 4.8 \\
\hline & 2 & 0.136 & 1.28 & 1.07 & 0.52 & 9.3 & 14.6 \\
\hline & 3 & 0.083 & 0.73 & 0.66 & 0.35 & 23.2 & 5.1 \\
\hline & 4 & 0.088 & 0.94 & 0.74 & 0.58 & 8.9 & 7.0 \\
\hline & 5 & 0.131 & 1.06 & 0.86 & 0.32 & 13.6 & 11.6 \\
\hline & 6 & 0.111 & 1.45 & 0.82 & 0.75 & 8.6 & 13.5 \\
\hline & 7 & 0.098 & 0.76 & 0.65 & 0.23 & 25.1 & 6.3 \\
\hline & 8 & 0.110 & 1.22 & 1.06 & 0.58 & 7.2 & 11.3 \\
\hline & 9 & 0.083 & 0.65 & 0.60 & 0.31 & 18.4 & 4.5 \\
\hline & 10 & 0.084 & 0.92 & 0.59 & 0.23 & 24.0 & 6.5 \\
\hline & 11 & 0.131 & 1.42 & 0.96 & 0.59 & 9.3 & 15.6 \\
\hline & 12 & 0.105 & 1.09 & 0.96 & 0.46 & 10.2 & 9.6 \\
\hline & 13 & 0.104 & 0.92 & 0.83 & 0.47 & 14.6 & 8.1 \\
\hline & 14 & 0.102 & 1.36 & 1.16 & 0.66 & 6.7 & 11.6 \\
\hline & 15 & 0.096 & 1.07 & 0.90 & 0.55 & 9.4 & 8.6 \\
\hline
\end{tabular}


positive time scale even for aggregates that decreased their velocity only slightly while limiting the effect of noise. These metrics were calculated for each aggregate individually and compared to aggregate size and vertical density difference.

\section{RESULTS}

\section{Experimental results}

Data of settling behavior for all 39 aggregates observed in the 2-layer aggregate settling experiments are given in Table 2. It is important to note that aggregates that form in roller tanks are generally denser than those formed in nature, and thus typically exhibit much higher settling velocities than aggregates observed in situ (Shanks 2002). Thus, aggregates used in this study may be more representative of dense nearshore aggregates (which contain more mineral material) rather than offshore aggregates formed from phytoplankton blooms.

All aggregates demonstrated a settling velocity minimum when passing through the density transition (Table 2). However, the extent to which the aggregates decreased their velocity varied between aggregates, as well as among experiments.

The most striking differences in settling behavior occurred between aggregates in Expt 1 and aggregates in the other 3 experiments (Fig. 4). The 5 aggregates in Expt 1 all demonstrated a VMSV less than or equal to 0 (within the resolution of our images) when passing through the density transition. Although some of the aggregates had a negative NMSV, all except for Aggregate 2 were within the error (due to video recording noise) of having a 0 minimum settling velocity. By contrast, the NMSV of the aggregates in Expts 2, 3, and 4 ranged from 0.08 to 0.89 , with a mean value of 0.53 (Fig. $4 \mathrm{~A}$ ). This difference between Expt 1 and the other 3 experiments is also evident in the DST, which ranged between 104.6 and $600.6 \mathrm{~s}$ for Expt 1 (mean of $258.1 \mathrm{~s}$ ), and between 1.0 and $45.4 \mathrm{~s}$ for Expts 2, 3, and 4 (mean of 11.9 s) (Fig. 4B). The large spread in DSTs observed within a given experiment is expected because of the wide range of aggregate shapes and sizes used in the experiments. Although aggregates from each of the 4 experiments represent a range of sizes, it is important to note that the largest aggregate in Expt 1 was more than 3 times larger (by equivalent spherical diameter) than any of the other aggregates, and likewise its delayed settling time was much longer and not representative of the rest of the aggregates tested. The different settling behaviors are exemplified in plots of aggregate vertical location and settling velocity over time for an aggregate from Expt 1 (Fig. 5A,B) and for an aggregate from Expt 4 (Fig. 5C,D).

Differences also occurred in the manner in which DST varied with aggregate equivalent spherical diameter, which ranged between $0.051 \mathrm{~cm}$ and $0.658 \mathrm{~cm}$ for all experiments (mean of $0.121 \mathrm{~cm}$ ) (Table 2). DST for aggregates in Expt 1 showed a strong positive linear relationship with equivalent spherical diameter $\left(r^{2}=0.988, p<0.001\right.$; Fig 6A). However, the other 3 experiments - when grouped together-showed a negative but not significant relationship between DST and aggregate equivalent spherical diameter (Fig. 6B). When Expts 2, 3, and 4 were considered separately, only Expt 3 showed a significant relationship at the $\mathrm{p}=0.05$ level $\left(\mathrm{r}^{2}=0.398, \mathrm{p}=0.028\right)$.

Although many experimental parameters differed among the experiments, one particularly notable difference between Expt 1 and the other 3 experiments was the initial excess density of the aggregates in
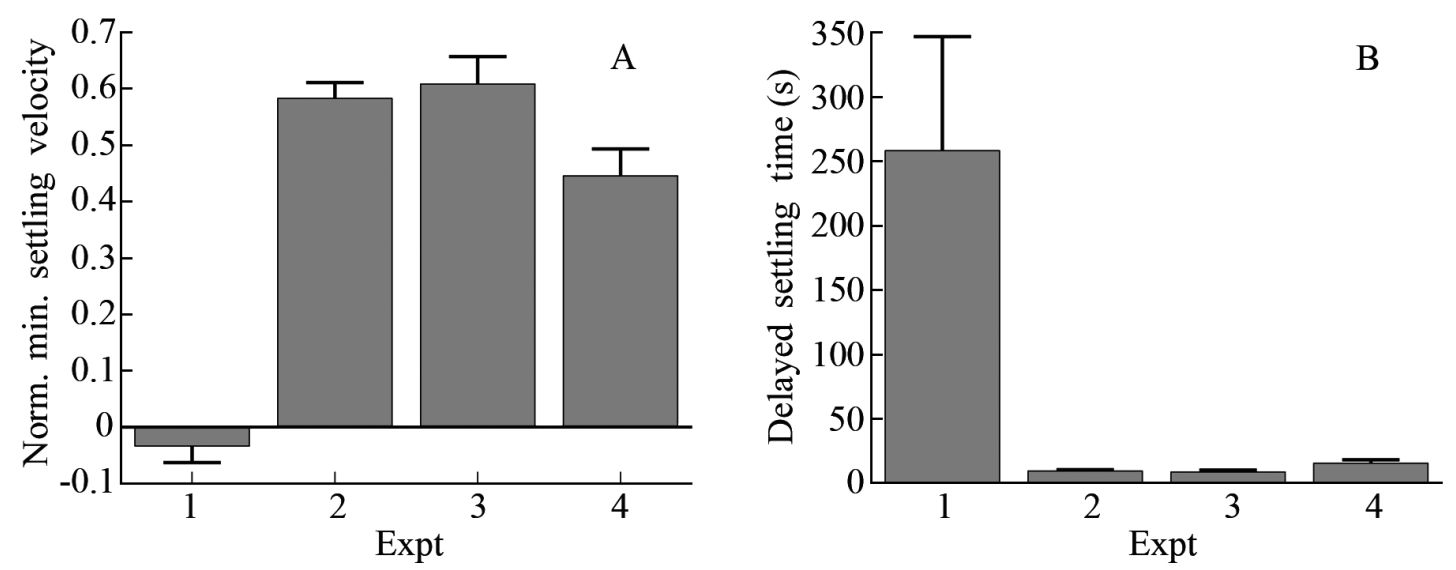

Fig. 4. Mean (A) normalized minimum settling velocity and (B) delayed settling time for aggregates in each experiment. Error bars $=$ standard error 

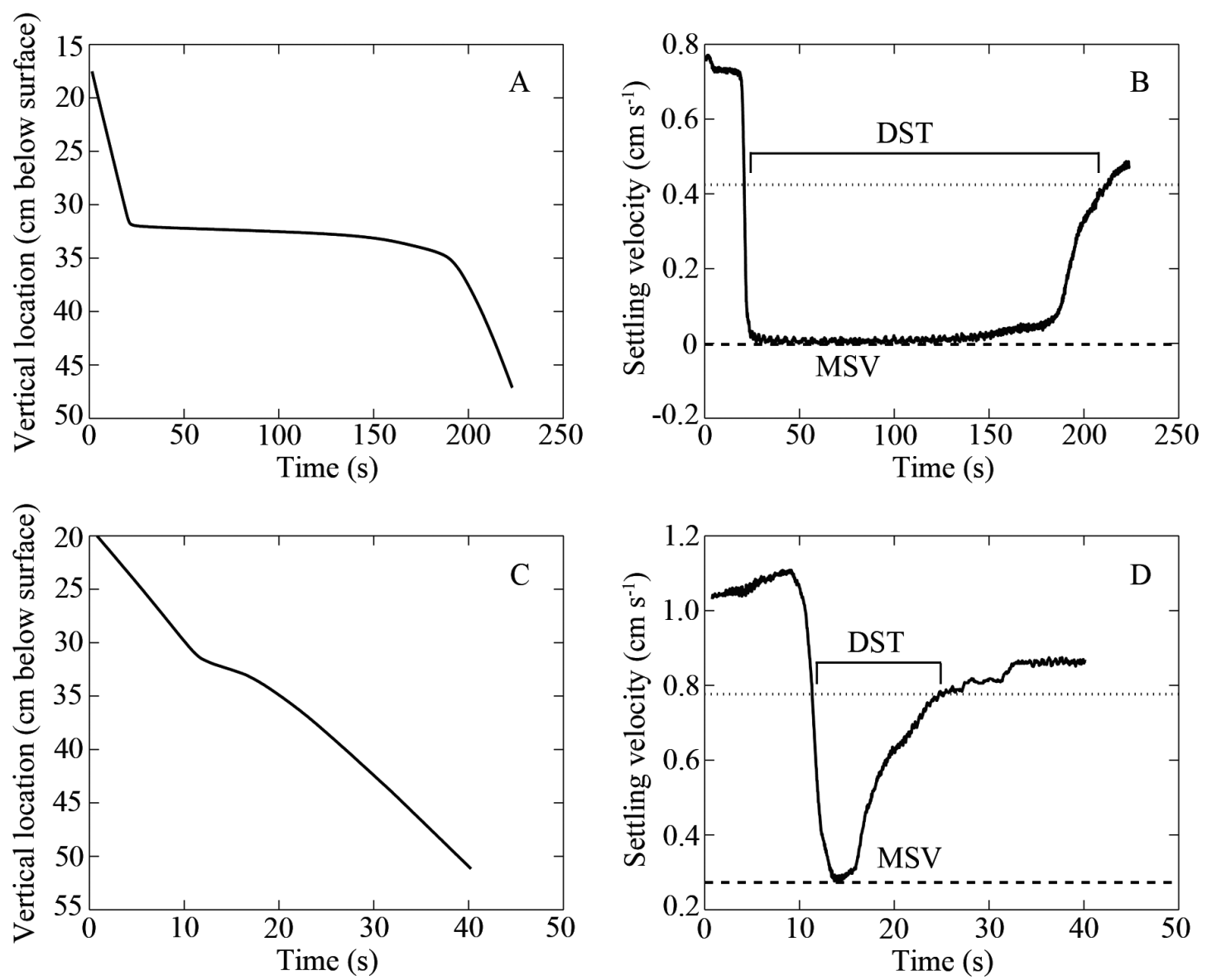

Fig. 5. Settling behavior of 2 aggregates through a sharp density transition. (A) Aggregate vertical location over time for Aggregate 3 from Expt 1. (B) Smoothed aggregate settling velocity over time for the same aggregate as in (A). (C) Aggregate vertical location over time for Aggregate 5 from Expt 4. (D) Smoothed aggregate settling velocity over time for same aggregate as in (C). In plots (B) and (D), the dashed line shows the minimum settling velocity (MSV, not normalized) and the dotted line represents $90 \%$ of the terminal velocity in the bottom layer, which was used to find delayed settling time (DST, shown with brackets)

the bottom layer (Table 1). The aggregates in Expt 1 were less dense than the bottom layer fluid initially (a negative excess density) while the aggregates in Expts 2, 3, and 4 were more dense than the bottom layer fluid (a positive excess density).

\section{Comparison of experimental results to models}

The observed relationships between aggregate size and DST (Fig. 6A \& B) can be used to determine the dominant mechanism of delayed settling for each experiment by comparing the relationships with theoretical predictions of particle settling behavior from 2 different models. The first model-hereafter referred to as the porous particle model-illustrates the settling behavior of a porous particle as it passes through a sharp density transition. A brief description of the model is given here, but specific details of this model_-ongoing in development—will be published elsewhere (R. Camassa, S. Khatri, R. M. McLaughlin, J. C. Prairie, B. L. White, S. Yu unpubl. data). The settling behavior in this model does not include any entrainment of fluid around the particle; thus, any decrease in particle settling velocity at the density transition is strictly due to diffusion-limited retention. The model assumes: (1) the Re is much smaller than 1, (2) a spherical particle whose size is not changing in time, (3) a density gradient formulated as an error function, (4) the ambient density gradient does not diffuse during the total time that it takes the sphere to settle through the transition region, (5) the radius of the sphere is small compared to variations in the ambient density profile, and (6) the time scale of diffusion into the sphere is small relative to the particle settling time scale. Under these assumptions, the model can be formulated as a force balance between the drag forces acting on the particle and buoyancy forces exerted by the fluid on the particle. The diffusion equation is solved dependent upon the location 

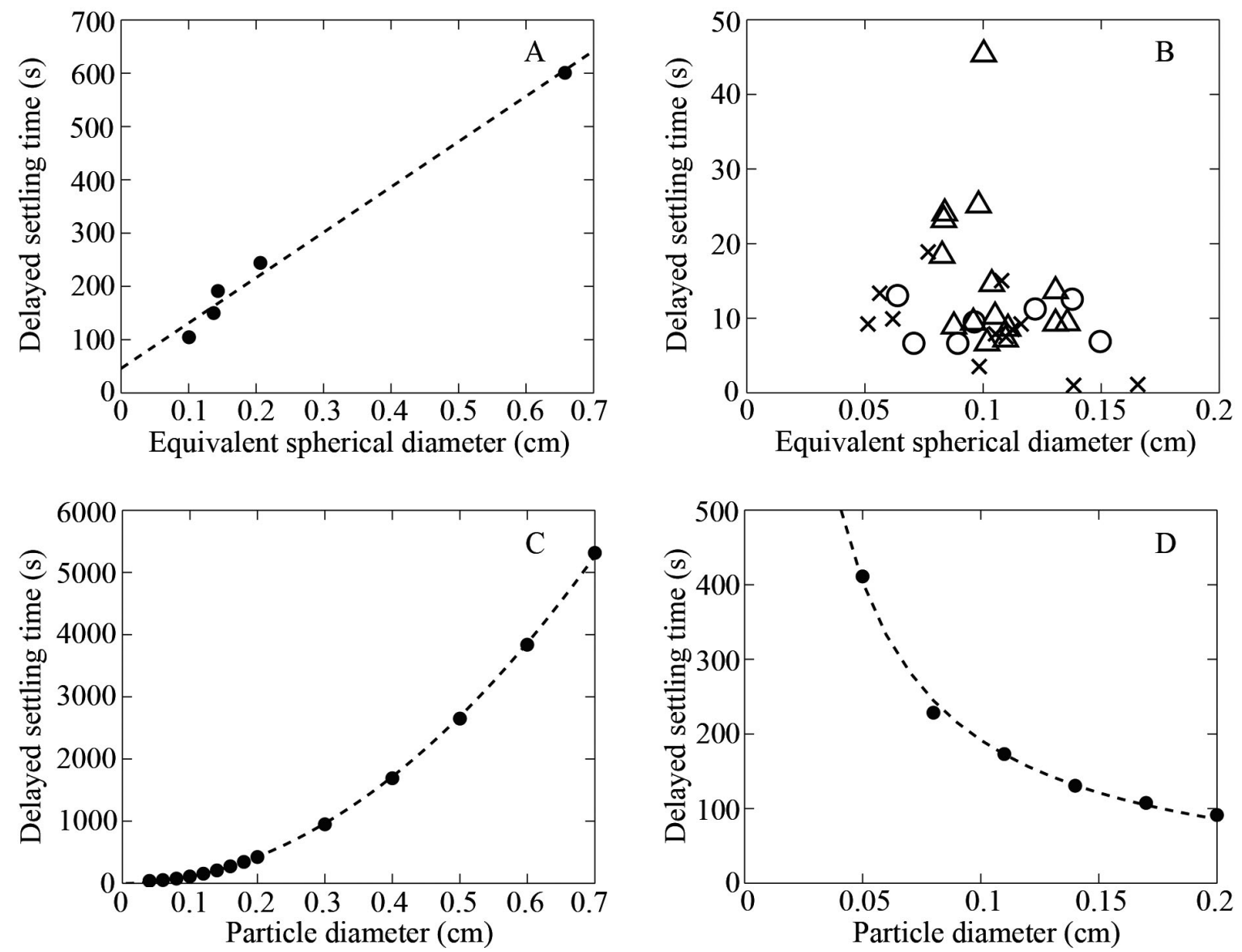

Fig. 6. (A) Aggregate equivalent spherical diameter vs. delayed settling time (DST) for all aggregates from Expt 1. Linear regression shown as dotted line $\left(y=851.1 x+46.2 ; p<0.001, r^{2}=0.988\right)$. (B) Aggregate equivalent spherical diameter vs. DST for all aggregates from Expts $2(\mathrm{O}), 3(\mathrm{X})$, and $4(\Delta)$. Linear regression was not significant when all data was grouped together at $\mathrm{p}$ $=0.05$. For each experiment calculated separately, only Expt 3 had a significant linear regression $(y=-99.2 x+18.7 ; p=0.028$, $\left.r^{2}=0.398\right)$. (C) DST for different particle diameters from the porous particle model. Model was run with parameters: density of the top layer $\left(\rho_{\mathrm{TL}}\right)=0.998 \mathrm{~g} \mathrm{~cm}^{-3}$, density of the bottom layer $\left(\rho_{\mathrm{BL}}\right)=1.04 \mathrm{~g} \mathrm{~cm}^{-3}$, particle porosity $(P)=0.98$, density of the solid fraction of the particle $\left(\rho_{\text {solid }}\right)=1.3 \mathrm{~g} \mathrm{~cm}^{-3}$, and diffusivity coefficient for salt $\left(\kappa_{\mathrm{S}}\right)=1.5 \times 10^{-5} \mathrm{~cm}^{2} \mathrm{~s}^{-1}$. Dashed line shows quadratic fit $\left(y=10747 x^{2}-2.4 ; p<0.001, r^{2}>0.999\right)$. (D) DST for different particle diameters from the solid particle entrainment model. Model was run with parameters: $\rho_{\mathrm{TL}}=1.36 \mathrm{~g} \mathrm{~cm}^{-3}, \rho_{\mathrm{BL}}=1.38 \mathrm{~g} \mathrm{~cm}^{-3}$, and particle density $\left(\rho_{\text {particle }}\right)=1.48 \mathrm{~g} \mathrm{~cm}^{-3}$. Dashed line shows a fit of the form $y=1 / x\left(y=21.2(1 / x)-19.9 ; p<0.001, r^{2}=0.995\right)$. The different curves shown in (C) and (D) demonstrate that delayed settling due to diffusion limited retention results in a positive (quadratic) relationship between DST and aggregate size while entrainment of lighter fluid results in a negative relationship between DST and aggregate size

of the sphere to determine how much salt has diffused into the fluid within the sphere and therefore determines the weight of the sphere. Also, the buoyancy force is dependent upon the ambient fluid density surrounding the particle. By solving the diffusion equation analytically, we have developed a nonlinear integro-differential equation for the position of the particle as a function of time, which is then solved using numerical methods. Parameters in the model include density of the top layer $\left(\rho_{\mathrm{TL}}\right)$, density of the bottom layer $\left(\rho_{\mathrm{BL}}\right)$, diffusivity coefficient for salt $\left(\kappa_{\mathrm{S}}\right)$, the particle porosity $(P)$, and the density of the solid fraction of the particle $\left(\rho_{\text {solid }}\right)$.
This model was run for particle diameters ranging from 0.04 to $0.7 \mathrm{~cm}$ and the DST was calculated for each particle diameter in the same way as for the experimental results. These preliminary simulations demonstrate a positive correlation between particle diameter and DST that was fit with a quadratic polynomial $\left(\mathrm{r}^{2}>0.999\right.$; Fig. 6C). The model was formulated at low Re (the Stokes flow regime) since there is an analytical formula for the drag force in this case (Batchelor 1967). However, simulations using an empirical drag law for larger Re numbers, the White drag law (White 1974), showed no significant differences in the observed trends presented here while 
having a minor decrease in the magnitude of the DST ( $<10 \%$ for all particle diameters tested).

The second model-hereafter referred to as the solid particle entrainment model—gives the settling behavior of a solid particle as it passes through a sharp density transition (Camassa et al. 2009, 2010). This previously developed model illustrates decreased settling velocity at the density transition due to entrainment of lighter fluid; diffusion plays no role in the delayed settling of the particle since the particle is not porous. The model assumes: (1) the Re is much smaller than 1, (2) a spherical particle, (3) a density profile represented by a step function, and (4) neglects the effects of molecular diffusion. Parameters include $\rho_{\mathrm{TL}}, \rho_{\mathrm{BL}}$, and the particle density $\left(\rho_{\mathrm{par}}\right.$ ticle). A full description of the formulation and assumptions of the model can be found in Camassa et al. (2009). The model was run for particle diameters ranging from 0.05 to $0.2 \mathrm{~cm}$, and the DST was calculated for each particle diameter. This model predicts a negative correlation between particle diameter and delayed settling time that was fit with a curve of the form $y=1 / x\left(r^{2}=0.995\right.$; Fig $\left.6 \mathrm{D}\right)$.

The predictions from the models presented in Fig. 6C \& D provide insight into the relationship between particle size and DST for each of the 2 mechanisms for delayed settling. The formulation of these models allows us to consider each mechanismentrainment and diffusion-limited retention-separately. Although such a perspective does not reflect real conditions for the experiments in which both mechanisms play a role and are likely interacting, it helps us gain an understanding of the conditions under which one mechanism may be more important than the other. Other important differences between the experiments and the models include particle shape (which is assumed to be spherical in the models) and Re (which is assumed to be less than 1 in the models). For these reasons, we do not attempt to directly compare the experimental and theoretical results, but instead compare trends between particle size and delayed settling time that might provide information about the underlying mechanisms.

The porous particle model predicts a positive quadratic relationship between particle diameter and DST. This relationship is expected since the mechanism that controls the retention time of the particle at the density transition is diffusion, and the time scale of diffusion is proportional to particle radius squared. By contrast, the solid particle entrainment model predicts a negative hyperbolic relationship between particle diameter and DST. This relationship can also be explained by the underlying mechanism, since the decrease in particle settling speed should be regulated by the volume of the entrained lighter fluid (proportional to the surface area) relative to the volume of the particle. We therefore may expect that the DST is proportional to the surface area to volume ratio, which for a sphere scales as $1 / R$, where $R$ is the particle radius.

The strong positive correlation between aggregate size and DST for Expt 1 (Fig. 6A) suggests that the settling behavior of these aggregates was driven primarily by diffusion-limited retention. The relationship observed between aggregate size and DST was linear rather than the quadratic relationship predicted by the porous particle model (Fig. 6C). The discrepancies observed between the model and experiments - both in the magnitude of the DST and the shape of the relationship between particle size and DST - are most likely due to the assumption of a spherical particle, lack of entrainment in the model, and the parameterization of the model used here. Although the model assumes the particles are spherical, the aggregates used in the experiments often had irregular shapes, particularly the larger particles; this will increase particle surface area at which diffusion takes place, resulting in lowered DSTs relative to equivalently-sized spherical particles. Additionally, although the porous particle model only includes delayed settling due to diffusion-limited retention, both diffusion-limited retention and entrainment played a role (likely interacting) in the delayed settling of each of the aggregates in the experiments, even if one mechanism dominated the observed behavior. Lastly, the parameter values for $P$ and $\rho_{\text {solid }}$ used in the model simulations presented here represent estimates from literature and other experiments (Alldredge \& Gotschalk 1988, Ploug et al. 2008); however, these may not reflect the actual properties of the aggregates used in the experiments.

Other characteristics of aggregate settling behavior from Expt 1 also suggest that diffusion-limited retention was the dominant mechanism. For example, all aggregates in Expt 1 had a settling velocity of zero at the density transition, as expected for particles exhibiting diffusion-limited retention. In addition, the DSTs for the aggregates in Expt 1 were on average more than an order of magnitude larger than for the other 3 experiments.

The weak negative relationship between aggregate size and DST for Expts 2, 3, and 4 (although significant only for Expt 3) suggests that the settling behavior for these experiments may be dominated primarily by entrainment of lighter fluid. The nonsignificant relationships between aggregate size and 
DST in Fig. 6B are likely due to the large range in aggregate shapes observed in these experiments. However, the non-zero minimum settling velocities for all aggregates in Expts 2, 3, and 4 and the relatively short DSTs (as compared to Expt 1) further suggest that entrainment of lighter fluid is more important than diffusion in these cases. As for Expt 1, the discrepancies in DST values between the solid particle entrainment model and Expts 2, 3, and 4 can be explained by the model assumption of a spherical particle, lack of diffusion in the model, and the model parameterization.

\section{DISCUSSION}

\section{Predicting the dominant mechanism for delayed settling at density transitions}

The sinking behavior of aggregates through sharp density transitions observed in both the experimental data and model simulations provides insight into the circumstances under which the decreased settling velocity at the transition is primarily driven by diffusion-limited retention (Fig. 1B) or entrainment of lighter fluid (Fig. 1A). When the density of the aggregate in the top layer fluid is less than the density of the bottom layer fluid, the aggregate will have to stop at the density transition until sufficient diffusion into the particle allows it to continue to sink. However, when the density of the aggregate in the top layer fluid is greater than the density of the bottom layer fluid, the aggregate can continue settling through the density transition but experiences a decrease in settling velocity because of fluid entrained from the top layer. Thus, the curve

$$
\rho_{\mathrm{BL}}=\rho_{\mathrm{a}}
$$

divides 2 broad regimes: above this curve, diffusionlimited retention controls the particle's delayed setting at the density transition, although there may be important interactions with the effects due to entrainment; below this curve, diffusion is no longer important and the dominant mechanism for delayed settling is entrainment of lighter fluid.

The 2 regimes described by Eq. (4) are shown in Fig. 7A. For the 4 experiments conducted, the settling behavior regime can be identified easily from the initial excess density of the aggregate in the bottom layer (Table 1). When this excess density is positive, the density of the aggregate is greater than the density of the bottom layer fluid, thus placing it in the entrainment regime. Likewise, when this excess density is negative, the aggregates fall in the diffusionlimited retention regime. It is important to note that the regimes represented in Fig. 7 simply depict relative effects of one mechanism compared to the other, rather than an absolute trend. For example, in the entrainment regime, moving further away from the dividing line indicates that the effect of entrainment becomes stronger relative to the effect of diffusionlimited retention; it does not indicate that the effect of entrainment becomes stronger in an absolute sense. In fact, in a study of solid spheres settling
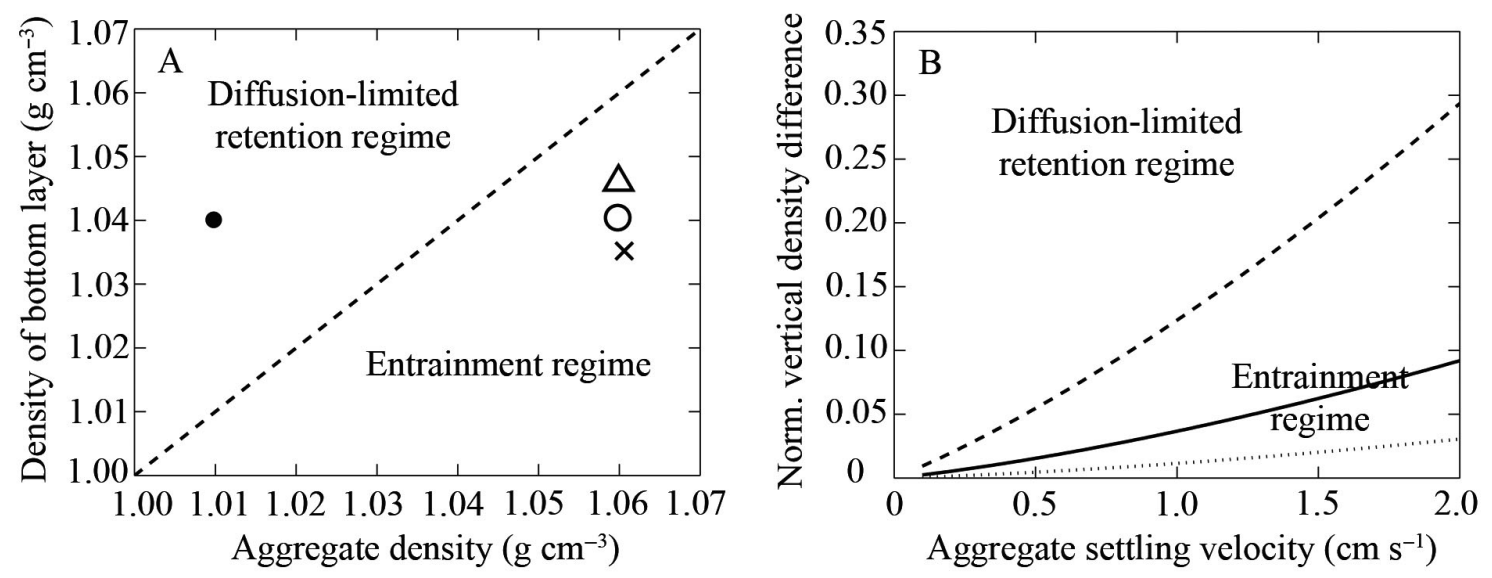

Fig. 7. Two aggregate sinking behavior regimes for an aggregate passing through a sharp density transition. (A) Aggregate density vs. bottom layer density. The curve (Eq. 4) separates the regime dominated by diffusion-limited retention (above the curve) and the regime dominated by entrainment of lighter fluid (below the curve). (๑) Expt 1, (O) Expt 2, (X) Expt 3, and ( $\Delta$ ) Expt 4. (B) Aggregate sinking velocity vs. normalized layer density. Several curves of Eq. (6) are shown for different values of aggregate radius $(R): R=0.025 \mathrm{~cm}$ (dashed line), $R=0.05 \mathrm{~cm}$ (solid line), and $R=0.1 \mathrm{~cm}$ (dotted line). For each curve, the region above the curve represents the regime dominated by diffusion-limited retention and the region below the curve represents the regime dominated by entrainment of lighter fluid 
through density transitions, the effect of entrainment was observed to become stronger as the density of the sphere became closer to the density of the bottom layer fluid (R. Camassa, R. M. McLaughlin, A. Vaidya unpubl. data).

Moreover, although one mechanism can be dominant in certain cases, both mechanisms are always at work to some extent, and interactions between them can alter the delayed settling behavior. Particularly for the diffusion-limited retention regime, although diffusion is necessary for the particle to increase its density and thus continue to sink, the effects of entrainment have been shown to be important in many cases, particularly in accurately predicting delayed settling times (R. Camassa, S. Khatri, R. M. McLaughlin, J. C. Prairie, B. L. White, S. Yu unpubl. data).

The 2 regimes can also be described as a function of settling velocity, which is more easily measured in the field than aggregate density. By combining Eq. (4) with Eq. (1) — which provides an estimate of aggregate density (in top layer fluid) as a function of settling velocity and aggregate size — the following curve is obtained:

$$
\rho_{\mathrm{BL}}=\frac{3 U^{2} \rho_{\mathrm{TL}} C_{\mathrm{D}}}{8 g R}+\rho_{\mathrm{TL}}
$$

Eq. (5) can be rewritten so that a normalized measure of the vertical density difference $\left(\rho_{\mathrm{BL}}-\rho_{\mathrm{TL}}\right) / \rho_{\mathrm{TL}}$ is expressed in terms of aggregate settling velocity and radius:

$$
\frac{\rho_{\mathrm{BL}}-\rho_{\mathrm{TL}}}{\rho_{\mathrm{TL}}}=\frac{3 U^{2} C_{\mathrm{D}}}{8 g R}
$$

For given aggregate radii, a curve of this normalized vertical density difference vs. settling velocity can be calculated; in the same way as for Eq. (4), above the curve represents delayed settling primarily driven by diffusion-limited retention while below the curve represents delayed settling primarily driven by entrainment of lighter fluid. Fig. 7B illustrates several curves of the normalized vertical density difference vs. aggregate settling velocity for different aggregate radii. As before, both mechanisms can act to delay settling and interact with each other.

\section{Implications of delayed settling for aggregate thin layer formation}

The results of this study have shown that aggregates derived from natural waters can exhibit significantly decreased settling velocities when passing through sharp density transitions because of 2 differ- ent mechanisms: diffusion-limited retention and entrainment of lighter fluid. In some cases, aggregates demonstrated only a modest decrease in settling velocity (with a minimum settling velocity as large as $\sim 89 \%$ of the settling velocity in bottom layer), while in other cases, aggregates came to a complete stop. The DST reached up to $\sim 600 \mathrm{~s}$ in the most dramatic case observed; however, in the majority of cases the decrease in settling velocity was on the order of $\sim 10 \mathrm{~s}$, representing a relatively short-term event given the total time required for an aggregate to sink out of the surface ocean. However, the importance of this phenomenon is not the delay experienced by a single aggregate in its journey to depth, but rather, the resulting accumulation of aggregates at the depth of the density transition.

Even modest decreases in aggregate settling speed at sharp density transitions can result in significant local increases in aggregate abundance. Using a rough approximation-only considering the effects of settling speed-the local increase in aggregate abundance will equal the inverse of the NMSV. For example, a NMSV of 0.5 would result in a doubling in local aggregate concentration, even if the delayed settling time of an individual aggregate is only $\sim 10 \mathrm{~s}$. This model is overly simplistic, since it suggests that in cases where the NMSV equals 0, there would be an infinite buildup of aggregates. Including the effects of vertical diffusivity, as done in previous models of plankton thin layer formation (Stacey et al. 2007, Birch et al. 2008, Prairie et al. 2011), will provide a balance between the accumulation caused by the delayed settling and the dissipating effects of mixing, thus presenting a more realistic idea of how these mechanisms can affect vertical aggregate distributions.

The intensity of the resulting aggregate layer will depend strongly on whether the delay in aggregate settling is driven primarily by diffusion-limited retention or entrainment of lighter fluid. As demonstrated by this study, the decrease in settling velocity is more pronounced as well as longer-lasting for aggregates undergoing diffusion-limited retention. Thus, layers formed by this mechanism will demonstrate higher increases in aggregate concentrations compared to layers formed by entrainment of lighter fluid. However, even in the case where entrainment dominates, aggregate layers can form.

The persistence of aggregate layers would largely be determined by the persistence of the density transition that originally caused the decrease in settling velocity. If the sharp density gradient is transient, then the aggregate layer would also be expected to 
be ephemeral. However, in many cases sharp density gradients can persist for days or significantly longer in the ocean (Dekshenieks et al. 2001), thus allowing long-lived aggregate layers to form.

Aggregate layers have important effects on food web dynamics, acting as hot spots for zooplankton foraging. Studies have demonstrated that marine snow can be an important food source for a diverse variety of zooplankton, including protists, copepods, other mesozooplankton, and larval invertebrates (Alldredge 1972, Lampitt et al. 1993, Steinberg 1995, Shanks \& Walters 1996, 1997, Green \& Dagg 1997, Artolozaga et al. 2002). Aggregate layers formed through delayed settling may further enhance local zooplankton abundance and grazing, explaining the finding that up to $70 \%$ of aggregate carbon can be degraded by invertebrate grazers before an aggregate sinks out of the surface ocean (Kiørboe 2000). Laboratory experiments have shown that several taxa of zooplankton are able to seek out and remain in regions of high food concentration (Jakobsen \& Johnsen 1987, Tiselius 1992, Menden-Deuer \& Grünbaum 2006). For marine snow, zooplankton may be able to use chemical sensing to detect sinking particles (Jackson \& Kiørboe 2004, Kiørboe 2011). Field observations have demonstrated that the distributions and grazing rates of zooplankton and perhaps higher trophic levels such as small fish are often associated with planktonic layers (McManus et al. 2003, Benoit-Bird et al. 2009, 2010, Menden-Deuer \& Fredrickson 2010). However, there is still a need for studies of trophic interactions in aggregate layers in the field, since most studies of zooplankton grazing on aggregates have focused on zooplankton associations with single particles (Green \& Dagg 1997, Shanks \& Walters 1997, Jackson \& Kiørboe 2004). Continuing advances in optical and acoustic technology may allow for in situ measurements of the settling behavior and vertical distributions of aggregates concurrent with grazing rates and distributions of zooplankton and fish, providing a better mechanistic understanding of the role of delayed settling in aggregate layer formation and its impact on trophic interactions.

Aggregate layers may also be a hotspot for bacterial activity and organic matter remineralization. Experimental and theoretical studies have suggested that bacteria may preferentially find and colonize sinking aggregates (Kiørboe et al. 2001, 2002, Kiørboe \& Jackson 2001, Stocker et al. 2008). In addition, bacterial activity and enzymatic hydrolysis rates on aggregates can be several orders of magnitude higher than that of aggregate-free water (Grossart et al. 2007, Ziervogel \& Arnosti 2008, Ziervogel et al. 2010), demonstrating that aggregates not only represent regions of enhanced bacterial abundance but also active carbon remineralization. In aggregate layers formed by delayed aggregate sinking, the effect of aggregates as remineralization hot spots may be further strengthened. Given the potential for aggregate layers as hotspots for zooplankton foraging and bacterial activity, the presence of these layers may act to reduce local carbon flux, with implications for larger-scale carbon cycling.

\section{Applicability to aquatic ecosystems}

The experimental results presented here represent a small fraction of natural conditions found in aquatic ecosystems; however, the basic observation of delayed aggregate settling at sharp density transitions may be widely applicable to many regions of the world's oceans since the general dynamics underlying the delayed settling behavior will remain the same. The vertical density differences tested in the current study (with density differences of $\sim 1.025$ to $\sim 1.046 \mathrm{~g} \mathrm{~cm}^{-3}$ for the marine aggregates tested) are much greater and over shorter vertical distances than would be observed in most coastal regions or the open ocean (density for the entire water column will typically range from $\sim 1.02$ to $\sim 1.029 \mathrm{~g} \mathrm{~cm}^{-3}$ ). However, similar aggregate settling behavior may be observed at much weaker density gradients since the effect of density gradients on aggregate settling behavior is controlled not only by the sharpness of the gradient but also by the density of the aggregate. Since aggregates used in this study were formed in roller tanks, they are likely much denser than aggregates found in the open ocean and other regions outside of very nearshore environments (Alldredge \& Gotschalk 1988, Shanks 2002). For example, for natural marine aggregates from the San Pedro and Santa Barbara Basins, Alldredge \& Gotschalk (1988) measured a median aggregate density of $1.02502 \mathrm{~g}$ $\mathrm{cm}^{-3}$ (equal to $0.00014 \mathrm{~g} \mathrm{~cm}^{-3}$ higher than the ambient seawater). Thus, natural, less-dense aggregates in these systems are likely to exhibit significantly decreased settling velocities even with weaker density gradients than those tested in this study.

In some stratified aquatic environments, the density differences tested in this study are representative of naturally occurring gradients. In estuaries, for example, the transition from fresh water to seawater can occur over a relatively small vertical distance which can retain particles for extended periods of 
time, resulting in estuarine turbidity maxima, as has been observed in the Columbia River, USA, estuary (Crump et al. 1999). Under these conditions, carbon remineralization can be enhanced by particleattached bacteria (Crump et al. 1999). Furthermore, deep hypersaline basins, such as those in the Gulf of Mexico, the Red Sea, and the Mediterranean Sea, can exhibit up to an order of magnitude vertical change in salinity over very short depth scales (Polymenakou et al. 2007, Tribovillard et al. 2009). In these extreme environments, trapped particles at the halocline can affect the distribution, composition, and abundance of both organic matter and the microbial community (LaRock et al. 1979, Polymenakou et al. 2007, Tribovillard et al. 2009). In estuaries as well as hypersaline basins, the intense vertical density differences would make delayed settling by aggregates more likely to be driven by diffusion-limited retention, resulting in minimum settling velocities close to zero and resulting in very long particle residence times. These settling behavior attributes explain the intense particle accumulations often observed at these sites (Crump et al. 1999, Tribovillard et al. 2009).

Finally, it is important to consider whether the density gradients in question are driven by changes in salinity or temperature. In some parts of the ocean, vertical salinity variations can cause sharp pycnoclines (most notably in estuaries and hypersaline basins as discussed previously), thus mimicking the experiments presented here. However, most often in the upper ocean, temperature gradients are responsible for vertical changes in density. Since the molecular diffusion of heat occurs at a rate nearly 2 orders of magnitude faster than that of salt (Gargett et al. 2003), aggregates settling through temperaturedriven density gradients will likely exhibit decreases in settling velocity that are much more short-lived than those observed in this study.

\section{CONCLUSIONS}

These experimental results demonstrate that delayed settling of natural aggregates at density transitions can occur by 2 different mechanisms - entrainment of lighter fluid and diffusion-limited retention. The time scale and extent to which an aggregate decreases its velocity at the density transition depends on the dominant mechanism at work. A firstorder prediction of the conditions in which entrainment vs. diffusion-limited retention will dominate shows that the governing mechanism depends on the aggregate size, settling speed, and strength of the density gradient. However, since in many intermediate cases both mechanisms are important, future work exploring the interactions between these 2 mechanisms is needed. In addition, although we demonstrate decreased settling velocity across a range of aggregate sizes and conditions, further experimental work is needed to understand how settling behavior of natural aggregates varies with changing aggregate and environmental parameters, including porosity, aggregate density, aggregate size, and density gradient. Lastly, investigation on whether the settling behavior of aggregates (especially in highly concentrated regions) is affected by fluid interactions with other aggregates will provide a more complete understanding of aggregate settling dynamics.

The mechanisms for delayed settling of aggregates across density transitions illustrated here have important implications for both trophic dynamics and carbon cycling. Even modest decreases in aggregate settling velocities can result in significant accumulations of aggregates in layers that can act as hot spots for foraging by zooplankton (and subsequently higher trophic levels) in addition to bacterial remineralization. For both zooplankton grazing and bacterial activity, overlooking the impact of hot spots such as aggregate layers may cause total water column rates of these important processes to be significantly underestimated.

Acknowledgements. We thank A. Brandt, J. Dresser and A. Horne for their help with experimental work. Thanks to E. Monbureau for her technical help. We thank 3 anonymous reviewers whose comments greatly improved this manuscript. This work is funded primarily by NSF CMG ARC1025523 and additionally by NSF DMS-1009750, NSF RTG DMS-0943851, NSF RAPID CBET-1045653, NSF OCE0848703, and NSF GRFP DGE-0646083.

\section{LITERATURE CITED}

Abaid N, Adalsteinsson D, Agyapong A, McLaughlin RM (2004) An internal splash: levitation of falling spheres in stratified fluids. Phys Fluids 16:1567-1580

Alldredge AL (1972) Abandoned larvacean houses: a unique food source in the pelagic environment. Science 177: 885-887

Alldredge AL, Crocker KM (1995) Why do sinking mucilage aggregates accumulate in the water column? Sci Total Environ 165:15-22

Alldredge AL, Gotschalk C (1988) In situ settling behavior of marine snow. Limnol Oceanogr 33:339-351

- Alldredge AL, Silver MW (1988) Characteristics, dynamics, and significance of marine snow. Prog Oceanogr 20: 41-82

Alldredge AL, Cowles TJ, MacIntyre S, Rines JEB and others (2002) Occurrence and mechanisms of formation 
of a dramatic thin layer of marine snow in a shallow Pacific fjord. Mar Ecol Prog Ser 233:1-12

> Artolozaga I, Valcárcel M, Ayo B, Latatu A, Iriberri J (2002) Grazing rates of bacterivorous protists inhabiting diverse marine planktonic microenvironments. Limnol Oceanogr 47:142-150

Batchelor GK (1967) An introduction to fluid dynamics. Cambridge University Press, Cambridge

> Benoit-Bird KJ, Cowles TJ, Wingard CE (2009) Edge gradients provide evidence of ecological interactions in planktonic thin layers. Limnol Oceanogr 54:1382-1392

Benoit-Bird KJ, Moline MA, Waluk CM, Robbins IC (2010) Integrated measurements of acoustical and optical thin layers I: vertical scales of association. Cont Shelf Res 30: $17-28$

Birch DA, Young WR, Franks PJS (2008) Thin layers of plankton: formation by shear and death by diffusion. Deep-Sea Res I 55:277-295

Camassa R, Falcon C, Lin J, McLaughlin RM, Parker R (2009) Prolonged residence times for particles settling through stratified miscible fluids in the Stokes regime. Phys Fluids 21:031702

> Camassa R, Falcon C, Lin J, McLaughlin RM, Mykins N (2010) A first-principle predictive theory for a sphere falling through sharply stratified fluid at low Reynolds number. J Fluid Mech 664:436-465, doi:10.1017/ S0022112010003800

Cauwet G (2002) DOM in the coastal zone. In: Hansell DA, Carlson CA (eds) Biogeochemistry of marine dissolved organic matter. Academic Press, New York, NY

> Crump BC, Armbrust EV, Baross JA (1999) Phylogenetic analysis of particle-attached and free-living bacterial communities in the Columbia River, its estuary, and the adjacent coastal ocean. Appl Environ Microbiol 65:3192-3204

> Dekshenieks MM, Donaghay PL, Sullivan JM, Rines JEB, Osborn TR, Twardowski MS (2001) Temporal and spatial occurrence of thin phytoplankton layers in relation to physical processes. Mar Ecol Prog Ser 223:61-71

> Derenbach JB, Astheimer H, Hansen HP, Leach H (1979) Vertical microscale distribution of phytoplankton in relation to the thermocline. Mar Ecol Prog Ser 1:187-193

- Gargett AE, Merryfield WJ, Holloway G (2003) Direct numerical simulation of differential scalar diffusion in three-dimensional stratified turbulence. J Phys Oceanogr 33:1758-1782

> Green EP, Dagg MJ (1997) Mesozooplankton associations with medium to large marine snow aggregates in the northern Gulf of Mexico. J Plankton Res 19:435-447

Grossart HP, Tang KW, Kiørboe T, Ploug H (2007) Comparison of cell-specific activity between free-living and attached bacteria using isolates and natural assemblages. FEMS Microbiol Lett 266:194-200

> Hedges JI, Oades JM (1997) Comparative organic geochemistries of soils and marine sediments. Org Geochem 27:319-361

> Jackson GA (1994) Particle trajectories in a rotating cylinder: implications for aggregation incubations. Deep-Sea Res I 41:429-437

> Jackson GA, Kiørboe T (2004) Zooplankton use of chemodetection to find and eat particles. Mar Ecol Prog Ser 269: 153-162

> Jakobsen PJ, Johnsen GH (1987) Behavioural response of the water flea Daphnia pulex to a gradient in food concentration. Anim Behav 35:1891-1895

Kindler K, Khalili A, Stocker R (2010) Diffusion-limited retention of porous particles at density interfaces. Proc Natl Acad Sci USA 107:22163-22168

Kiørboe T (2000) Colonization of marine snow aggregates by invertebrate zooplankton: abundance, scaling, and possible role. Limnol Oceanogr 45:479-484

Kiørboe T (2011) How zooplankton feed: mechanisms, traits and trade-offs. Biol Rev Camb Philos Soc 86:311-339

Kiørboe T, Jackson GA (2001) Marine snow, organic solute plumes, and optimal sensory behavior of bacteria. Limnol Oceanogr 46:1309-1318

Kiørboe T, Ploug H, Thygesen UH (2001) Fluid motion and solute distribution around sinking aggregates. I. Smallscale fluxes and heterogeneity of nutrients in the pelagic environment. Mar Ecol Prog Ser 211:1-13

> Kiørboe T, Grossart HP, Ploug H, Tang K (2002) Mechanisms and rates of bacterial colonization of sinking aggregates. Appl Environ Microbiol 68:3996-4006

> Lampitt RS, Wishner KF, Turley CM, Angel MV (1993) Marine snow studies in the Northeast Atlantic Ocean: distribution, composition and role as a food source for migrating plankton. Mar Biol 116:689-702

- LaRock PA, Lauer RD, Schwarz JR, Watanabe KK, Wiesenburg DA (1979) Microbial biomass and activity distribution in an anoxic, hypersaline basin. Appl Environ Microbiol 37:466-470

MacIntyre S, Alldredge AL, Gotschalk CC (1995) Accumulation of marine snow at density discontinuities in the water column. Limnol Oceanogr 40:449-468

McManus MA, Alldredge AL, Barnard AH, Boss E and others (2003) Characteristics, distributions, and persistence of thin layers over a 48 hour period. Mar Ecol Prog Ser 261:1-19

> Menden-Deuer S, Fredrickson K (2010) Structure-dependent, protistan grazing and its implication for the formation, maintenance and decline of phytoplankton patches. Mar Ecol Prog Ser 420:57-71

Menden-Deuer S, Grünbaum D (2006) Individual foraging behaviors and population distributions of a planktonic predator aggregating to phytoplankton thin layers. Limnol Oceanogr 51:109-116

> Ploug H, Passow U (2007) Direct measurement of diffusivity within diatom aggregates containing transparent exopolymer particles. Limnol Oceanogr 52:1-6

Ploug H, Iversen MH, Fischer G (2008) Ballast, sinking velocity, and apparent diffusivity within marine snow and zooplankton fecal pellets: implications for substrate turnover by attached bacteria. Limnol Oceanogr 53: 1878-1886

Polymenakou PN, Stephanou EG, Tselepides A, Bertilsson S (2007) Organic matter preservation and microbial community accumulations in deep-hypersaline anoxic basins. Geomicrobiol J 24:19-29

> Prairie JC, Franks PJS, Jaffe JS (2010) Cryptic peaks: invisible vertical structure in fluorescent particles revealed using a planar laser imaging fluorometer. Limnol Oceanogr 55:1943-1958

Prairie JC, Franks PJS, Jaffe JS, Doubell MJ, Yamazaki H (2011) Physical and biological controls of vertical gradients in phytoplankton. Limnol Oceanogr Fluids Environ 1:75-90

> Shanks AL (2002) The abundance, vertical flux, and stillwater and apparent sinking rates of marine snow in a shallow coastal water column. Cont Shelf Res 22: 2045-2064

> Shanks AL, Edmondson EW (1989) Laboratory-made artifi- 
cial marine snow: a biological model of the real thing. Mar Biol 101:463-470

Shanks AL, Walters K (1996) Feeding by a heterotrophic dinoflagellate (Noctiluca scintillans) in marine snow. Limnol Oceanogr 41:177-181

Shanks AL, Walters K (1997) Holoplankton, meroplankton, and meiofauna associated with marine snow. Mar Ecol Prog Ser 156:75-86

Simon M, Grossart HP, Schweitzer B, Ploug H (2002) Microbial ecology of organic aggregates in aquatic ecosystems. Aquat Microb Ecol 28:175-211

Smith DC, Simon M, Alldredge AL, Azam F (1992) Intense hydrolytic enzyme activity on marine aggregates and implications for rapid particle dissolution. Nature 359: 139-142

Srdi -Mitrovi AN, Mohamed NA, Fernando HJS (1999) Gravitational settling of particles through density interfaces. J Fluid Mech 381:175-198

Stacey MT, McManus MA, Steinbuck JV (2007) Convergences and divergences and thin layer formation and maintenance. Limnol Oceanogr 52:1523-1532

Steinberg DK (1995) Diet of copepods (Scopalatum vorax) associated with mesopelagic detritus (giant larvacean houses) in Monterey Bay, California. Mar Biol 122: 571-584

Stocker R, Seymour JR, Samadani A, Hunt DE, Polz MF

Submitted: July 2, 2012; Accepted: April 29, 2013
(2008) Rapid chemotactic response enables marine bacteria to exploit ephemeral microscale nutrient patches. Proc Natl Acad Sci USA 105:4209-4214

Tiselius P (1992) Behavior of Acartia tonsa in patchy food environments. Limnol Oceanogr 37:1640-1651

Tribovillard N, Bout-Roumazeilles V, Sionneau T, Serrano JCM, Riboulleau A, Baudin F (2009) Does a strong pycnocline impact organic-matter preservation and accumulation in an anoxic settling? The case of the Orca Basin, Gulf of Mexico. CR Geoscience 341:1-9

White FM (1974) Viscous fluid flow. McGraw-Hill, New York, NY

Yick KY, Torres CR, Peacock T, Stocker R (2009) Enhanced drag of a sphere settling in a stratified fluid at small Reynolds numbers. J Fluid Mech 632:49-68

Ziervogel K, Arnosti C (2008) Polysaccharide hydrolysis in aggregates and free enzyme activity in aggregate-free seawater from the north-eastern Gulf of Mexico. Environ Microbiol 10:289-299

Ziervogel K, Forster S (2005) Aggregation and sinking behaviour of resuspended fluffy layer material. Cont Shelf Res 25:1853-1863

Ziervogel K, Steen AD, Arnosti C (2010) Changes in the spectrum and rates of extracellular enzyme activities in seawater following aggregate formation. Biogeosciences $7: 1007-1015$

Proofs received from author(s): May 30, 2013 